\title{
Primeira Exposição de Desenho Infantil e Juvenil do Paraná uma renovação no conceito das exposições escolares (1943)
}

\author{
DULCE REGINA BAGGIO OSINSKI \\ Universidade Federal do Paraná, \\ Curitiba, PR, Brasil
}

RESUMO

O artigo analisa a Primeira Exposição de Desenho Infantil e Juvenil realizada em Curitiba/PR, no ano de 1943, e suas relações com as tendências modernas em arte e educação. O evento envolveu intelectuais e artistas como Raul Gomes, Erasmo Pilotto, Helena Kolody e Guido Viaro, além de professorandas e alunos de escolas públicas e particulares. Defendendo a liberdade de expressão e a individualidade da criança, o projeto da exposição justificava sua importância com caráter científico, baseado em pesquisas sobre o desenho infantil, realizadas na área da psicologia por Luquet, Rouma e Rabello, assim como nas conclusões do Congresso de Ensino de Desenho de Paris, de 1937. Como fontes, foram utilizados os impressos diários $O$ Dia e a Gazeta do Povo.

PALAVRAS-CHAVE

exposições de arte infantil; história da educação no Paraná; imprensa e educação. 


\title{
FIRST EXHIBITION OF CHILDREN'S AND YOUTH DRAWING IN PARANÁ: A RENEWAL OF THE CONCEPT SCHOOL EXHIBITIONS (1943)
}

\author{
ABSTRACT \\ This article analyzes the First Exhibition of Children's and Youth Drawing, \\ held in Curitiba/PR, in 1943, and its relations with the modern trends in art \\ and education. The event involved intellectuals and artists such as Raul Gomes, \\ Erasmo Pilotto, Helena Kolody and Guido Viaro, in addition to students and \\ soon-to-be teachers from public and private schools. Advocating freedom \\ of expression and the individuality of children, the project's rationale was its \\ scientific character, based on research on children's drawings developed in \\ psychology by Luquet, Rouma and Rabello, as well on the conclusions of the \\ Paris Drawing Education Conference, held in 1937. The sources used were \\ the daily newspapers ODia and Gazeta do Povo. \\ KEYWORDS \\ children's art-exhibition; history of education in Paraná; press and education.
}

\section{PRIMERA EXPOSICIÓN DE DIBUJO INFANTIL Y JUVENIL DEL PARANÁ: UNA RENOVACIÓN EN EL CONCEPTO DE LAS EXPOSICIONES ESCOLARES (1943)}

\section{RESUMEN}

El artículo analiza la primera Exposición de Dibujo Infantil y Juvenil realizada Curitiba/PR, en 1943, y sus relaciones con las tendencias modernas en arte y educación. El evento involucró intelectuales y artistas como Raul Gomes, Erasmo Pilotto, Helena Kolody y Guido Viaro, además de las profesoras en formación y alumnos de escuelas públicas y privadas. Defendiendo la libertad de expresión y la individualidad del niño, el proyecto de la exposición justificaba su importancia por su carácter científico, con base en investigaciones sobre el dibujo infantil, realizadas en psicología por Luquet, Rouma y Rabello, así como en las conclusiones del Congreso de Enseñanza de Dibujo de París, de 1937. Como fuentes se utilizaron los diarios impresos O Dia y la Gazeta do Povo.

PALABRAS CLAVE

exposición de arte infantil; historia de la educación en el estado de Paraná; prensa y educación. 


\section{INTRODUÇÃO}

Um certame original e inédito. Com esse título, o jornal curitibano O Dia (28 nov. 1943, p. 4) anunciava para dezembro de 1943 a inauguração da Primeira Exposição de Desenho Infantil e Juvenil do Paraná. ${ }^{1}$ Proposta pela Sociedade Amigos de Alfredo Andersen, a mostra foi patrocinada pela Diretoria Geral de Educação do estado e organizada pela Escola de Professores de Curitiba, ${ }^{2}$ trazendo como protagonistas as crianças curitibanas, especialmente as oriundas de escolas públicas.

Um olhar mais atento aos jornais do período pode contribuir para desvelar aspectos contextuais que possibilitaram a concretização de tal iniciativa: seus pressupostos, modos de organização, recepção pelo público e avaliação da intelectualidade local. Os impressos diários são veículos privilegiados por "registrar, explicar, discutir e comentar as coisas do mundo" (Campos, 2012, p. 48). Interpretado como mecanismo de intervenção, o texto jornalístico atua muitas vezes no intuito de "demarcar e fixar normas de pensar que se expressam como valores, juízos, modos de classificação, enfim, justificativas para a ação social” (Vieira, 2007, p. 14).

$\mathrm{Na}$ grande imprensa da Curitiba de 1943, podemos perceber dois temas recorrentes relacionados às discussões que aqui terão lugar: a atenção dedicada à criança e a prática da realização de exposições, que por meio de evidências materiais ou iconográficas procurava disseminar informações, ideias e posições políticas.

Criada em 1933, a Semana da Criança tinha alcance nacional e atuava como instrumento de propaganda governamental, articulando ações educativas e de saneamento entre as secretarias estaduais. Promovida pelo Departamento Nacional da Criança, criado pelo Governo Vargas em 1940, funcionava como estratégia de conscientização e de conquista de apoio para as causas da infância, combatendo o desamparo. Tinha como motivação os índices considerados na época alarmantes, como a mortalidade infantil, com taxa de 270 por mil nascidos vivos no Distrito Federal (Tarefas de alta relevância, 18 dez. 1943, p. 8), o analfabetismo, que no Paraná girava em torno de 50\% (O ensino público nacional, 22 dez. 1943, p. 4.), ou o fato de metade das crianças brasileiras em idade escolar se encontrar fora da escola (A palavra do ministro da Educação, 17 set. 1943, p. 4).

Em Curitiba, a Semana da Criança de 1943, organizada pela Diretoria Geral da Educação, em colaboração com os municípios e instituições de assistência social, abrangeu uma programação variada (Criança, 5 out. 1943, p. 4), que incluía desfiles e festas escolares, palestras e competições atléticas (Programa das comemorações...,

1 Nas fontes consultadas, constatou-se, além dessa denominação, também referência à Primeira Exposição de Arte Infantil e Juvenil e à Exposição Infantil e Juvenil de Artes Plásticas. Neste artigo serão utilizadas ocasinalmente tais denominações, de acordo com as referências nas fontes consultadas.

2 Embora o decreto n. 6.597, de 15 de março de 1938, tenha transformado as escolas normais do estado em escolas de professores (Miguel, 1997, p. 68-74), algumas fontes ainda se referem à instituição como escola normal. 
9 out. 1943, p. 3), motivando a imprensa local a publicar artigos com temas correlatos, muitos deles tendo como foco a criança abandonada (Correia, 1943, p. 4).

O jornal O Dia abordou os direitos da criança brasileira, explicitando a esperança nela depositada para um futuro melhor e prescrevendo que esta deveria "ser tratada como criança, e como tal respeitada e atendida nos seus justos interesses e aspirações" (Direitos da criança brasileira, 10 out. 1943, p. 3). Parcerias governamentais, como a firmada pela Legião Brasileira de Assistência em colaboração com a Associação de Puericultura do Paraná, igualmente receberam espaço com matérias que enalteciam as realizações oficiais em favor da infância (A proteção à infância..., 29 out. 1943, p. 4).

Paralelamente às festividades direcionadas à criança, as exposições de arte vinham em destaque na programação cultural da cidade. Em setembro, o artista Theodoro de Bona inaugurava uma mostra no Clube Curitibano. Discípulo de Alfredo Andersen, o pai da pintura do Paraná, De Bona (1904-1990) gozava de prestígio em âmbito nacional, tendo uma de suas obras no acervo da Pinacoteca do Estado de São Paulo (Exposição do pintor..., 7 set. 1943, p. 3). Na ocasião, Oswaldo Pilotto, diretor do Colégio Estadual do Paraná, determinou às suas alunas que visitassem a mostra, e Erasmo Pilotto, mentor técnico da Escola de Professores, propôs visita monitorada ao evento (Gomes, 1943, p. 4).

O artista e professor Guido Viaro (1897-1971), italiano que se estabelecera em Curitiba na década de 1930, também expôs, no mês de outubro, pinturas e aquarelas em espaço situado à Praça Zacarias (Exposição Guido Viário, 5 out. 1943, p.3), e o Clube Curitibano abrigaria o Salão da Primavera ${ }^{3}$ (Será inaugurado hoje..., 12 out. 1943, p. 8). Durante o mês de novembro, o Salão de Arte da Prefeitura Municipal de Curitiba receberia ainda o Sexto Salão Anual de Arte Fotográfica (Freyesleben, 26 nov. 1943, p. 4).

Outras mostras de caráter mais geral também agitavam a rotina da capital do estado. A Segunda Grande Exposição de Curitiba, configurada nos moldes das grandes exposições universais, popularizadas a partir da segunda metade do século XIX, ocupava cerca de trinta mil metros quadrados da Praça Rui Barbosa, localizada no centro da cidade. Representações da modernidade e vitrines dos inventos e mercadorias produzidos pela indústria, esses eventos tinham também um caráter pedagógico, dado seu “efeito de demonstração' das crenças e virtudes do progresso, da produtividade, da disciplina do trabalho, do tempo útil, das possibilidades da técnica, etc." (Pesavento, 1997, p. 14). Tal espírito pode ser observado na edição curitibana, que pretendia mostrar ao público paranaense "o progresso financeiro do Paraná, suas possibilidades econômicas, a realidade de sua policultura, a curva ascensional dos 49 municípios, o vigor da indústria e do comércio" atuando como "índice de progresso geral do Paraná e demonstrativo da capacidade de trabalho de seu povo" (Um espelho fiel..., 12 dez. 1943, p. 5).

3 O Primeiro Salão Primavera foi um evento artístico em formato de exposição organizado pelo Clube Curitibano em 1943, movimentando a classe artística paranaense. 
Outro tipo de tradição no período eram as exposições escolares que, ao lado dos exames, das festas de final de ano e dos desfiles, podem ser vistas como "práticas simbólicas que, no universo escolar, tornaram-se uma expressão do imaginário sociopolítico da República" (Souza, 1998, p. 241). Seu surgimento relaciona-se com a instituição da escola primária graduada, baluarte do regime republicano, tendo também ligações com mostras similares realizadas no interior das exposições universais e das exposições pedagógicas (idem, p. 264). Por meio delas, a escola se abria à sociedade, tornando visíveis os resultados dos esforços de professores e alunos ao fazer a apresentação de trabalhos manuais, cadernos, provas e outros tipos de documentos relacionados ao cotidiano da escola.

$\mathrm{Na}$ Curitiba da década de 1940, as exposições escolares, ocupando escolas e outros espaços da cidade, congregavam assistência numerosa, fazendo parte do calendário escolar e constituindo-se em programa obrigatório para a comunidade local. Em 1943, alguns grupos escolares ${ }^{4}$ e instituições, como o Clube de Menores do Instituto de Jovens Brasileiros (Trabalhos dos alunos..., 3 out. 1943, p. 3), foram objeto de notícias que descreviam os materiais expostos em suas mostras. De maneira geral, os materiais expostos apresentavam as atividades desenvolvidas em sala de aula, privilegiando resultados que confirmassem a excelência do ensino ministrado ao longo do ano. Diferiam, assim, dos objetivos declarados por propostas mais focadas na autoexpressão e nas fases do desenvolvimento da criança, como o caso da Exposição de Desenhos de Crianças Inglesas.

Organizada por Herbert Read no contexto da Segunda Grande Guerra, tal iniciativa fazia parte de uma política de boa vizinhança entre os países aliados, refletindo tanto as pesquisas em torno das relações entre o desenho e a psicologia infantil, como as tendências de valorização da expressão artística livre da criança. A apreciação da arte dita "primitiva" e o desenvolvimento da arte moderna foram citados por Read, em texto de apresentação, como decisivos para "trazer a arte infantil para o critério geral da apreciação estética” (Read apud INEP, 1980, p. 27).

A exposição viajou por diversos países da Europa e América Latina. No Brasil, circulou por São Paulo e Minas Gerais, sendo primeiramente realizada no Museu Nacional de Belas Artes, no Rio de Janeiro, em 1941. Ali, os trabalhos apresentados atraíram uma grande multidão (INEP, 1980, p. 25-26), que se impressionou com a espontaneidade dos desenhos e pinturas das crianças, fruto de esforços que vinham sendo empreendidos na Inglaterra por educadores como Marion Richardson.

Em sua passagem por Curitiba, a mostra de Read foi considerada significativa por proporcionar aos educadores "abundância de material para estudos pedagógicos"

4 Foram mencionados pela imprensa: Grupo Escolar Barão do Rio Branco, Escola de Aplicação (Exposição de trabalhos..., 19 nov. 1943, p. 2), Grupo Escolar Prieto Martinez, Grupo Escolar Xavier da Silva, Grupo Escolar Água Verde (Exposição de trabalhos..., 25 nov. 1943, p. 3), Grupo Escolar Conselheiro Zacarias (Exposição de trabalhos..., 27 nov. 1943, p. 3), Grupo Escolar Tiradentes (Grupo Escolar Tiradentes, 30 nov. 1943, p. 3) e Grupo Escolar Professor Cleto (Exposição de trabalhos..., 23 nov. 1943, p. 6). 
(Trabalhos de arte..., 16 ago. 1942, p. 2). Promovida pela Sociedade Brasileira de Cultura Inglesa e organizada pela Diretoria Geral da Educação, teve lugar no Orfeão da Escola Normal e no saguão da Biblioteca Municipal em agosto de 1942 (idem, ibidem), sendo vista por educadores e alunos, pela intelectualidade local e pela comunidade em geral. Encantando os paranaenses pelas "lindas manifestações do talento da infância britânica revelados em um sem número de trabalhos" (As iniciativas interessantes, 9 nov. 1943, p. 4), foi motivadora para futuros empreendimentos que uniriam arte e educação.

Dois dos possíveis visitantes da mostra em Curitiba foram Erasmo Pilotto (1910-1992) e Raul Gomes (1889-1975), intelectuais identificados com as ideias renovadoras para a educação e que acreditavam ter a arte um importante papel nos processos de formação humana. Pilotto atuava como professor e assessor técnico da Escola Normal. Raul Gomes, signatário do Manifesto dos Pioneiros pela Educação Nova (1932) e presidente da Sociedade Amigos de Alfredo Andersen, era intelectual comprometido com a organização da cultura, conforme conceito cunhado por Gramsci (2004). Comungando ideais relacionados às interfaces entre arte e educação, os dois reuniram esforços para a realização de um empreendimento que pudesse, ao mesmo tempo, dar visibilidade à referida sociedade e às opções pedagógicas da escola normal.

\section{O PROJETO, A ORGANIZAÇÃO, A MONTAGEM}

Raul Gomes (Sociedade Amigos..., 14 dez. 1943, p. 4) relatou como a ideia da realização de uma exposição de crianças foi apresentada a Pilotto e qual foi sua reação:

Uma manhã, subia eu a escadaria da Escola Normal sob o peso de certos pensamentos ligados à exiquibidade [sic] do plano, quando defrontei aquele mestre. Notando meu ar preocupado, indagou-me da sua origem. Quando lhe falei na causa, teve uma de suas efusões de alacridade, e, propondo-me mobilizar forçar para a realização do projeto, garantiu-me que tudo seria fácil, simples.

Ele montaria a exposição, ele obteria até financiadores para ela, e para prêmios. Arregalei os olhos diante daquele insólito desfile de promessas e esperanças.

Assumindo a organização da mostra, prevista inicialmente para inaugurar em $1^{\circ}$ de dezembro de 1943, Erasmo Pilotto deu início aos trabalhos, nomeando uma comissão formada por ele, pelos professores Oswaldo Pilotto, Helena Kolody, Oswaldo Lopes e Ledi Cid, e pelo pintor Curt Waldemar Freyesleben. O projeto recebeu apoio integral do interventor Manoel Ribas, da Diretoria Geral da Educação e do Departamento Estadual de Imprensa e Propaganda (As iniciativas interessantes, 9 nov. 1943, p. 4).

O segundo passo foi a divulgação do evento nos jornais da cidade e na rádio $\mathrm{PRB}-2$, além de telegramas terem sido enviados a instituições educacionais do interior. Foram organizadas comissões de alunas e professorandas da Escola de Professores, que visitaram grupos escolares, escolas isoladas, colégios e ginásios da 
cidade, explicando as finalidades da exposição e seu funcionamento, e solicitando aos professores de desenho e aos diretores que enviassem quem tivesse "vocação para as artes plásticas” à comissão para receber instruções sobre a participação no evento (Exposição Infantil..., 11 nov. 1943, p. 4).

O plano inicial da mostra previa a existência de quatro seções. A primeira, de metodologia, contemplaria a Escola de Professores, o Grupo Tiradentes e a Escola de Aplicação, anexa à Escola de Professores. A segunda seção, com candidatos de jardins de infância, escolas públicas primárias e particulares, ginásios e colégios secundários e escola de professores, conteria dois setores, o de investigação pré-vocacional e o de investigação propriamente artística, com três subdivisões: crianças até 7 anos, crianças de 7 a 10 anos e jovens de 10 a 18 anos. A terceira seção se destinava à Escola Alfredo Andersen e à Escola Guido Viaro, especializadas em arte, e a quarta seção compreenderia "manifestações de particularidades e curiosidades relativas às artes plásticas no campo do desenho, pintura, modelagem e escultura e artes decorativas" (idem, ibidem). A concessão de prêmios objetivava incentivar a participação de crianças e adolescentes, e as manifestações de apoio financeiro foram noticiadas pelo jornal O Dia (Exposição Infantil..., 11 nov. 1943; Exposição de Arte..., 21 nov. 1943).

A imprensa local elencava, entre os objetivos do certame, a "descoberta ou sondagem vocacional para as artes plásticas” (A próxima Exposição..., 14 nov. 1943, p. 7), além da realização de um balanço da "capacidade criadora da criança e da juventude curitibana” (Exposição Infantil..., 18 nov. 1943, p. 8). À questão recorrente do talento e da vocação somava-se a ideia de que a convocação deveria "atingir todos os setores sociais, já no sentido horizontal,já no vertical, sem nenhuma distinção de classe, cor, religião, partido, etc.” (idem, ibidem):

[...] cada um de nós que conheça uma vocação existente em nosso lar, no dum vizinho, dum parente, amigo ou simples concidadão deve encaminhá-la com urgência à tal comissão. A Sociedade Amigos de Alfredo Andersen quer a mobilização de todas as tendências artísticas para revelá-las, animá-las e auxiliá-las em alguns casos. (A próxima Expopsição..., 14 nov. 1943, p. 7)

As crianças inscritas eram submetidas a uma prova geral para verificação de suas habilidades artísticas, realizada com cerca de quinhentos candidatos em idade variável de 3 a 18 anos. Procedimento semelhante, denominado em 1913 por Rouma (1947) de "método de enquete", era recorrente nas investigações sobre as relações entre psicologia e desenho infantil desde meados do século XIX e era considerado estratégia importante para a compreensão dos modos de pensar, sentir e se desenvolver das crianças. $\mathrm{O}$ autor cita experiências congêneres como as de Earn Barnes, nos Estados Unidos, de Kerschensteiner, na Alemanha, de Claparède, na Suíça, e a dele próprio, na Bélgica. No Brasil, Sylvio Rabello (1935) realizou, na década de 1930, investigação semelhante com crianças pernambucanas, aplicando a prova de desenho idealizada por Decroly e utilizada anteriormente por Faria de Vasconcelos com alunos portugueses. Diferentes da proposta paranaense por não terem caráter seletivo, esses testes operavam, para investigações científicas de 
problemáticas diversas, com base nos desenhos classificados como espontâneos. Não havia orientação prévia e a temática era livre ou provocada por narrativa de histórias ou fábulas.

Assistidas diretamente pelos professores organizadores da Primeira Exposição de Desenho Infantil e Juvenil, as professorandas encarregadas dos trabalhos preliminares dividiram os candidatos em duas turmas para realização dos testes, que consistiam na interpretação de um tema sugerido pela comissão organizadora. À primeira turma, composta de alunos do Jardim de Infância e do primeiro ano do curso primário, foi contada uma "singela fábula com poucos personagens" (Um certame original..., 28 nov. 1943, p. 4), cujo objetivo era captar as formas de expressão. Já ao segundo grupo de alunos, do segundo ano do curso primário ao segundo ano dos cursos ginasiais, em virtude de "seu maior desenvolvimento mental, uma complicada história de fadas forneceu os motivos de expressão através da menção de várias situações especiais, descrição de cenas e paisagens, traços mais vivos dos tipos invocados na história, etc." (idem, ibidem). Embora se tratasse de um teste seletivo, a organização afirmou que "em ambos os tipos de história, houve um estímulo à imaginação criadora” (idem, ibidem).

As provas foram encaminhadas para o artista Guido Viaro que, embora não participasse oficialmente da comissão constituída, foi convidado a proceder à seleção, envolvendo-se no processo de organização da exposição. Os critérios utilizados estariam de acordo com o "maior grau de imaginação revelado, sem se ater ao mecanismo da perfeição dos traços" " "de acordo com as idades concorrentes" (idem, ibidem), indicando respeito aos processos de expressão próprios da criança em suas diferentes fases de desenvolvimento. Os autores dos 86 trabalhos selecionados foram então convocados a realizar uma prova final, que já não tinha caráter eliminatório. Prevendo a eventualidade de uma execução inferior na segunda prova, "talvez pela influência de fatores psicológicos determinados pela preocupação do trabalho definitivo para o certame" (idem, ibidem), era admitida a hipótese do aproveitamento dos primeiros desenhos.

As inscrições para a participação na exposição tinham encerramento previsto para o dia 20 de novembro. Porém, três dias mais tarde, O Dia anunciava que os interessados ainda poderiam se dirigir à comissão organizadora (Exposição Infantil..., 23 nov. 1943, p. 2). Já nos dias 26 e 29 de novembro, anúncios convocaram nominalmente algumas crianças para a realização dos trabalhos finais, devendo elas se apresentarem munidas do material necessário, livremente escolhido por elas (Exposição Infantil..., 30 nov. 1943, p. 8; Exposição Infantil..., 26 nov. 1943, p. 2).

Essa decisão de ampliar a oportunidade de participação pode ter levado ao adiamento do cronograma do certame. Outro fator que contribuiu foram os preparativos de seleção final e montagem, um esforço conjunto da equipe envolvida no projeto, com a colaboração da prefeitura, que providenciou as "armações com iluminação adequada” (Exposição de Desenho..., 11 dez. 1943, p. 4).

Para cada trabalho foi feita uma moldura de papelão - o passe-partout. Essa prática, originária das artes plásticas, tinha como objetivo dar destaque aos desenhos individualmente. Os trabalhos foram montados nas paredes do Orfeão da Escola Normal e organizados dentro de painéis maiores, de acordo com cada proposta. 
Como podemos perceber na Figura 1, a disposição foi feita de maneira que preenchesse o espaço da parede, vertical e horizontalmente.

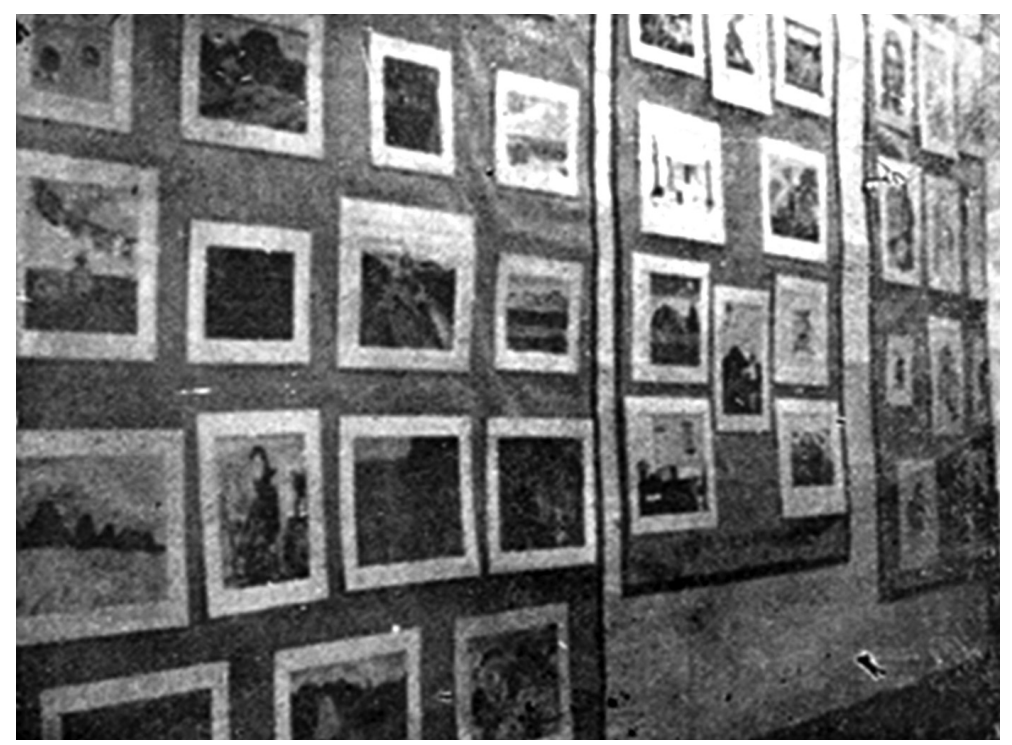

Figura 1 - Primeira Exposição Infantil e Juvenil de Desenho no Orfeão da Escola Normal. Fonte: Exposição de Desenho Infantil e Juvenil, 14 dez. 1943, p. 3.

Elaboração da autora.

Artigos publicados sobre a mostra ressaltavam o caráter científico da proposta, bem como sua atualidade e originalidade, afirmando ser a primeira vez que Curitiba recebia um certame de tal natureza, "baseado em elementos psicopedagógicos de investigação da vocação artística de crianças em idades que variam de 3 a 18 anos"(Um certame original..., 28 nov. 1943, p. 4). Os métodos aplicados se inspiravam

[...] num conjunto de experiências de indiscutível valor pedagógico, rigorosamente controladas em seus trabalhos práticos e realizadas de acordo com as observações sobre as aptidões infantis nos domínios da expressão e características das diversas etapas de desenvolvimento psicológico da criança. (idem, ibidem)

A mostra foi descrita como uma tentativa de materializar um processo em andamento, no intuito de pesquisar as vocações artísticas infantis por meio de métodos racionais, fugindo de qualquer critério de improvisação. Seus passos obedeceriam a uma "técnica uniforme", ajustando-se a "seguros elementos retirados de experiências correlatas e processadas depois de amadurecidos e exaustivos estudos sobre a psicologia e a capacidade expressionista da infância" (Exposição de Desenho..., 16 dez. 1943, p. 3). A experiência seria responsável por "abrir novas perspectivas aos trabalhos de investigação das tendências artísticas", possibilitando a adoção de 
critérios para a organização das exposições escolares e a afirmação de parâmetros renovados com relação ao papel do desenho nos currículos escolares (idem, ibidem).

A imprensa local advertia, ainda, o público a não ir "ao recinto da exposição atrás de emoções estáticas consequentes à contemplação de quadros de desenho artístico, obediente a raras e primorosas técnicas", pois a proposta consistia em "uma demonstração de como é, como se desenvolve, como se manifesta a tendência artística da criança, isto é, desde os 3 anos até a adolescência" (Exposição de Desenho..., 12 dez. 1943, p. 8). Considerava ser "um espetáculo simplesmente maravilhoso contemplar o autorear da alma infantil em suas expressões livres, espontâneas, provocadas mas dentro de certa liberdade" (idem, ibidem).

\section{A CONCRETIZAÇÃO DE UMA IDEIA: MODERNIDADE E DESENHO INFANTIL}

Finalmente, no dia 13 de dezembro de 1943, foi inaugurada a Primeira Exposição de Desenho Infantil e Juvenil, contando com a participação de autoridades governamentais e membros da sociedade. A presença de Saul Lupion de Quadros, diretor do jornal O Dia, sinaliza o apoio oficial dado por esse veículo ao evento, o que justifica a grande quantidade de artigos publicados em relação aos outros jornais locais. Entre os artistas presentes, foram citados Thorstein Andersen, João Turim e Theodoro de Bona. Também prestigiaram o certame os professores Erasmo Pilotto, Eloy Costa, Oswaldo Lopes e Adriano Robine, além de alunas da Escola de Professores e demais membros da comunidade. Mereceram destaque da imprensa a presença das professorandas, "verdadeiros elementos vivificadores do certame, a cujos preparativos e execução emprestaram o melhor de suas energias, inteligências, dedicação e perseverança" (Exposição de Desenho..., 14 dez. 1943, p. 8). O esforço das normalistas igualmente foi ressaltado no discurso de inauguração feito por Raul Gomes:

Elas se impregnaram do idealismo do seu mentor, elas visitaram grupos escolares, ginásios, [...] elas operaram as primeiras seleções, efetuaram todas as provas definitivas, elas agiram, elas abandonaram seus lazeres, elas consumiram horas nos gabinetes de psicopedagogia revolvendo material, organizando, providenciando sobre tudo, passando dias aqui, neste ambiente para a montagem deste certame. (Sociedade Amigos..., 14 dez. 1943, p. 4)

Após as solenidades de abertura, Gomes e Pilotto convidaram os presentes a visitarem a exposição, ministrando-lhes detalhadas explicações sobre sua organização e finalidades pedagógicas. Os cerca de quarenta painéis apresentavam trabalhos da Escola de Aplicação - anexa à Escola de Professores - do Grupo Escolar Tiradentes, da seção feminina do Ginásio Paranaense, do jardim de infância do Instituto Pestalozzi, dirigido por Erasmo Pilotto, e das escolas de pintura de Alfredo Andersen e Guido Viaro (Exposição de Desenho..., 14 dez. 1943, p. 8).

Alguns dias depois, o jornal O Dia publicaria a relação das crianças expositoras e as escolas às quais estavam vinculadas, que incluíam, além das anteriormente 
citadas, os grupos escolares Prieto Martinez, Zacarias, Rio Branco, 19 de Dezembro, Brandão, Professor Cleto, Pedro II, Xavier da Silva, Água Verde, o Colégio Estadual do Paraná, os institutos Santa Rita e Santa Maria e as Escolas Reunidas Novo Mundo (Exposição de Desenho..., 25 dez. 1943, p. 7).

Segundo o referido guia, os desenhos apresentados não deveriam ser considerados propriamente artísticos, pertencendo a uma categoria denominada "pré-vocacional". Referência ao ensino pré-vocacional pode ser encontrada na Constituição Federal de 1937, que o define como destinado às "classes menos favorecidas" e "primeiro dever do Estado" (Brasil, 1937).

Uma definição dos propósitos da exposição foi feita por Raul Gomes (Sociedade Amigos..., 14 dez. 1943, p. 4):

Ela é uma tentativa cautelosa de penetração nos domínios misteriosos da psique infantil e juvenil para se surpreender o surto e o processo de desenvolvimento, formação do senso e das vocações artísticas. Ninguém busque aqui esteticismo, tecnicidade, o espetacular e o ilusório.

Tudo isso foi sacrificado aos desígnios de um alto e nobre pensamento educativo à luz da verdade e ao rigor da ciência.

O caráter científico da mostra estaria ancorado, segundo Gomes (idem, ibidem), nos "preceitos dos mestres da psicopedagogia do desenho infantil-juvenil" e nas conclusões do "célebre Congresso de Paris", os quais "tiveram ampla corroboração e aplicação no material aí exposto cujo valor documentário se patenteia numa evidência solar".

O Congresso de Paris, de 1937, a que Gomes faz menção, é constantemente citado nos textos explicativos sobre a proposta da exposição e suas conclusões, de acordo com a imprensa, fazem referência “às diversas expressões de desenho nas diferentes idades, compreendendo desenho de letras, expressionismo aos 7 anos, desenho de medida [...], fonte de motivos expressionistas, desenho de fantasia, desenho de imaginação, desenho de memória, etc." (Um certame original..., 28 nov. 1943, p. 4). Esse comentário tratava provavelmente do Oitavo Congresso Internacional de Ensino de Desenho e de Artes Aplicadas, organizado simultaneamente à Exposição Internacional de Artes e Técnicas da Vida Moderna. Esta última recebeu cerca de 31 milhões de visitantes e, embora tivesse como tema principal "paz e progresso", no período tenso de entreguerras constituiu-se em um palco de demonstração e propaganda da identidade nacional e ideológica dos países representados. A orientação moderna da exposição, no que se refere ao campo artístico, fazia-se notar pela presença de personalidades como o arquiteto Le Corbusier, responsável pelo Pavilhão dos Tempos Novos (Feldman, 2006), e de Picasso, que expôs a obra Guernica, denúncia das atrocidades da Guerra Civil Espanhola.

Identificação semelhante com a modernidade na educação e na arte se fazia presente no Oitavo Congresso Internacional de Ensino de Desenho, anteriormente citado. Desde a década de 1930, o desenho livre na escola passou a ser defendido enfaticamente, e a polêmica sobre se os trabalhos infantis poderiam ser considerados obras de arte animava os círculos de artistas e educadores. $\mathrm{O}$ desenho de imaginação 
também passou a ser considerado uma boa abordagem de iniciação ao mundo da arte para as crianças, e questões como essas permearam os debates do evento. Argumentando que o desenho está relacionado a todas as atividades humanas e à compreensão dos segredos da natureza por não obedecer a fronteiras linguísticas, os participantes propunham estratégias para liberar os dons e combater as tiranias do academicismo ou da moda, advogando a favor de sua obrigatoriedade em todas as classes de liceus e colégios (Magne, 1938, p. 16).

Embora as temáticas privilegiassem as artes aplicadas e as relações entre arte e indústria, algumas discussões empreendidas no Oitavo Congresso versavam sobre o papel do desenho nas séries iniciais. Considerando que os erros de proporção ou de perspectiva são apenas interpretações feitas do ponto de vista dos adultos, os congressistas repudiavam qualquer intervenção nos desenhos de imaginação, devendo os de observação ser corrigidos segundo a evolução natural da criança. Mais importante que tudo, no ensino dessa disciplina seria necessário um bom conhecimento da psicologia infantil (Forster, 2009, p. 110-111) e o respeito à personalidade do indivíduo; o professor de desenho, como todo educador, deveria ser um psicólogo: antes de querer repreender, ele deveria procurar compreender. Também foi reafirmada a necessidade de formação específica do professor de desenho (Magne, 1938, p. 20-22).

A menção ao Congresso de Paris e a apropriação de suas ideias tinham também a intenção de dar à exposição realizada em Curitiba um referencial científico, ponto destacado por articulistas na ocasião. Embora tenha sido feita referência a um documento programático, localizamos apenas texto que sumariza as conclusões do congresso em linhas gerais (idem). É possível que Pilotto tenha tido contato com publicação em que questões mais específicas foram abordadas, como sugerem alguns de seus comentários na imprensa. Em contrapartida, podemos também considerar que ele tenha relacionado essas ideias gerais às propostas desenvolvidas. De qualquer maneira, há elementos coincidentes, a exemplo dos limites de idade de 3 a 18 anos para as pesquisas sobre os desenhos realizados, além dos pontos abordados a seguir.

Uma dessas referências foi a de que a orientação da exposição se pautaria pelas diretrizes do Congresso de Paris, de caráter "francamente expressionista". O desenho expressionista seria "aquele que interpreta uma ideia", abrangendo trabalhos de imaginação ou de memória com liberdade interpretativa. Já o desenho impressionista seria aquele "que é o resultado de uma impressão proveniente do exterior, em presença do modelo" (Exposição de Desenho..., 14 dez. 1943, p. 8), procedimento mais relacionado ao aprendizado tradicional de arte, que propõe exercícios com base na observação direta de elementos visuais.

Nas descrições dos painéis apresentados no certame, o congresso é citado algumas vezes para exemplificar relações com as artes aplicadas. É o caso do painel que apresentava desenhos de letras "compreendendo os seguintes passos: recorte das mesmas, procurar objetos semelhantes a elas por sua forma e enquadrar as formas dentro das letras"(idem, ibidem). Alguns trabalhos buscavam estabelecer relações do desenho com a escrita inicial corrente e artística, além daqueles que apresentavam "desenho expressionista aos 7 anos". Outros compreendiam o desenho de medidas, de fantasia e de imaginação, além do "desenho expressivo em todos os graus e 
cursos". Entre os itens abordados figuravam também "desenhos de memória com base na percepção imediata e desenho relacionado ao trabalho manual, compreendendo as tarefas de dobrar papéis, etc., desenhos de vinheta e aplicação no tecido" (idem, ibidem), além dos "desenhos de imaginação", feitos a partir da narração de uma história. Exercícios de desenho "métrico e rítmico, abrangendo ritmo da forma e ritmo da cor", foram igualmente mencionados, assim como trabalhos de papel recortado, gravados, caligrafia, desenho intuitivo de observação, desenho do natural, desenho decorativo e "contemplação artística" (idem, ibidem).

As relações entre a proposta da exposição e as teorias psicopedagógicas podem ter-se pautado na obra de Sylvio Rabello (1935), intitulada Psicologia do desenho infantil, por sua vez baseada nos teóricos e pesquisadores do desenho infantil Luquet (1910; 1927) e Rouma (1947), entre outros. Embora Rabello não seja citado nas fontes analisadas, algumas classificações e conceitos utilizados são coincidentes, tais como as categorias de "garatuja pré-intencional" e "garatuja intencional", "esquematismo", "realismo lógico" e "realismo visual" (Exposição de Desenho..., 14 dez. 1943, p. 8). Rabello, apoiado em Luquet (1910), define "garatuja pré-intencional", característica de trabalhos de crianças na idade até 3 anos, como "um amontoado de traços sem sentido [...], feita sem a intenção de representar alguma cousa", atividade de ordem motriz que constitui a primeira fase do desenho infantil, "manifestação elementar de movimentos gráficos” (Rabello, 1935, p. 160). O rabisco é visto como um brinquedo pelas crianças (Luquet, 1927), que se entretêm com o simples ato de rabiscar, dando-lhes interpretações diversas, dependendo do momento ou da sugestão de quem interroga (Rabello, 1935, p. 164). Foi o que observou Ledi Cid (1943, p. 7) com relação às crianças pequenas participantes da mostra, cujo "trabalho garatujador" imprimia "sobre a folha traços confusos pelas mesmas razões [:] prazer, descoberta, afirmação de personalidade" que as levam a "repetir palavras novas ou a desfazer um brinquedo".

No caso da "garatuja intencional", as crianças anunciam os objetos ao mesmo tempo em que desenham, manifestando o "desejo de representar alguma coisa", embora muitas vezes "seja esse desenho um amontoado informe de rabiscos" (Rabello, 1935, p. 166) que irá, paulatinamente, cedendo lugar a uma representação propriamente intencional. Já a fase do esquematismo, manifesta por volta dos 5 anos de idade, caracterizaria uma expressão gráfica figurativa por meio de esquemas ou elementos simbólicos simples (círculos, linhas etc.). Citando Kerschensteiner, Rabello afirma que os esquemas seriam como uma "espécie de recapitulação vaga das lembranças visuais da criança" (idem, p. 187). Outras menções podem ser percebidas pelo uso de expressões como "realismo lógico" e "realismo visual" (Exposição de Desenho..., 14 dez. 1943, p. 8), termos cunhados por Luquet (1910) e desenvolvidos por Rabello (1935). Para os autores, na fase do realismo lógico, considerado o apogeu da representação gráfica infantil, a criança busca "reproduzir dos objetos que pretende representar não somente o que pode ver, mas tudo o que neles se encontra e tudo o que sabe existir neles", sendo seu trabalho "mais descritivo que representativo, mais lógico do que visual” (Rabello, 1935, p. 197). Já no estágio do realismo visual, para o qual se encaminharia progressivamente a expressão da criança ao se tornar adulta, predominaria a ideia da representação em perspectiva (idem, p. 195). 
Segundo o roteiro publicado para a compreensão da mostra, todas as crianças participantes tinham realizado um desenho de imaginação, um desenho livre e um desenho de memória, categorias também utilizadas por especialistas da psicologia do desenho infantil em algumas pesquisas, como Claparède ${ }^{5}$ (Rouma, 1947, p. 26). Para a realização dos "desenhos de imaginação", fez-se uso da narração de histórias a serem interpretadas pelos candidatos, como no caso dos desenhos feitos por crianças de 6 anos, que se basearam numa história que contava de um João Grande que apanhava peixes, de um caranguejo que mordia o João Grande no pescoço, etc." (Exposição de Desenho..., 14 dez. 1943, p. 8). Da mesma maneira, a enquete feita por Barnes, em 1893, trabalhou com o conto João Boquiaberto, de Hofmann, escolhido por ser curto, simples, não conter objetos difíceis de desenhar e compreender dois acontecimentos distintos. $\mathrm{O}$ mesmo fez Claparède ao utilizar a interpretação da fábula $O$ lobo e a raposa em prova aplicada para sua pesquisa (Rouma, 1947, p. 19-26).

Alguns exemplos dos desenhos livres, que privilegiavam temáticas escolhidas pelas crianças, foram explorados pelo guia da exposição, como o que trazia uma "história completa, contada pela criança, de uma cozinheira, primeiro correndo no quintal para pegar galinhas, depois matando-as, vendo-se, ainda, as galinhas mortas e, em seguida, na panela”. Um dos trabalhos sobre essa temática trazia uma veia cômica, mostrando a galinha "enforcada, na frigideira, e, ao alto, numa atitude de pugilista que 'posa' para os fotógrafos jornalistas, via-se a 'mulher que matou a galinha"'(Cid, 1943, p. 7). Também foi mencionado, no guia, um desenho que narrava duas situações distintas, de natureza mais violenta, demonstrando atenção à realidade circundante: “[...] um desastre de automóvel; o ferido no chão, o automóvel que o vitimou, a admiração de um transeunte, e a ambulância que chega; [...] o incêndio da farmácia Minerva [e] a multidão emocionada em frente" (Exposição de Desenho..., 14 dez. 1943, p. 8). Outros temas foram citados por alguns visitantes da mostra, como o de um avião que deixava cair uma bomba na estrada, referência ao contexto de guerra, ou o de uma cena no hipódromo, diversão popular na época. Conforme descrição de Ledi Cid (1943, p. 7), "os espectadores espalhados no primeiro plano, todos voltados para uma parte da pista [...] em que se vê posicionados cavalo e cavaleiro. Adiante uma parte do campo do hipódromo, e além uma outra parte da pista".

Para Rouma (1947, p. 263), o desenho livre, considerado como forma de expressão, contribui para a averiguação da atividade intelectual da criança ao proporcionar indicações sobre o poder da imaginação. É capaz também de revelar as ideias que com maior frequência aparecem no campo da consciência, fornecendo informações sobre a exatidão de certos conceitos e sobre as influências do meio. Em contrapartida, possui valor representativo e auxiliar nas relações com outras áreas do conhecimento, como a linguagem, a história e a geografia.

5 A prova elaborada por Claparède e aplicada nas escolas de Vaud, Suíssa, continha quatro etapas: o desenho copiado (ou do natural), o desenho de memória, o desenho de ilustração (que corresponde ao de imaginação) e o desenho livre. 
O desenho de memória é citado em alguns experimentos investigativos, como o de Kerschensteiner (Rouma, 1947, p. 21-26), que convidou crianças para desenharem o retrato de seus familiares, animais, flores, árvores, um anjo ou uma igreja. Proposta análoga foi empreendida por Claparède, que solicitou aos participantes de sua pesquisa que desenhassem um gato (idem, ibidem). No caso da exposição aqui analisada, foram abordadas de memória temáticas relacionadas aos processos da natureza mediante a passagem do tempo, tendo sido representadas "frutas verdes, amadurecendo e maduras; frutas novas, desenvolvidas e velhas; flores fechadas, abertas e desfolhadas"; o "céu em dias claros, em dias de tempestade, em dias de chuva" (Exposição de Desenho..., 14 dez. 1943, p. 8). Outra experiência congênere foi a representação do carnaval (idem, ibidem); proposta que, por tratar de temas familiares aos desenhistas, tem similaridades com o teste aplicado por Kerschensteiner, que propôs a representação, pelos alunos, de uma batalha na neve (Rouma, 1947, p. 21).

A Escola de Aplicação apresentou trabalhos que foram considerados de orientação "expressionista" pelos organizadores. Além dos desenhos livres, foram expostos trabalhos feitos com base em uma aula de colorido, os quais representavam, com cores, os temas da guerra, da alegria e da preguiça (Exposição de Desenho..., 14 dez. 1943, p. 8). Esses resultados podem ter relação com experiências feitas por alunas do professor Oswaldo Lopes para um programa oficial, as quais impressionaram vivamente o ministro Capanema, quando de sua passagem por Curitiba no mês de setembro daquele ano (Exposição Infantil..., 24 nov. 1943, p. 4). Outra proposta apresentada por Lopes foi a comparação entre a planta de uma casa, desenhos geométricos do programa oficial de desenho e o trabalho espontâneo de uma aluna, exercício de abstração descrito como uma "surpreendente e sólida realização que revela esta tendência da pintura moderna, esta procura de uma forma, [...] de uma intimidade entre as coisas e as cores" (Leite, 1943). A Escola de Professores ainda apresentou trabalhos sobre o ensino do desenho da figura humana valendo-se de uma construção esquemática: "um menino jogando bola de burico; crianças batendo peteca e pulando corda, figuras esquemáticas realizadas após observação metódica, enriquecidas de atitudes e movimentos inesperados" (idem, ibidem).

A questão do talento ou da aptidão para o desenho, numa visão comparativa baseada em métodos supostamente científicos, era explicitada logo na entrada da exposição, em painel que confrontava a "mentalidade comum da criança e a mentalidade de duas crianças de grande capacidade, um demonstrando senso de construção, noção de amplidão, outro combinando linha completamente nova na figura humana" (idem, ibidem).

Nem todos os trabalhos, porém, expressavam as ideias professadas pelos pesquisadores do desenho infantil ou pelos participantes do Congresso de Paris. A política de inclusão de instituições, como as escolas de Andersen e Viaro, resultou possivelmente em trabalhos mais voltados para o aprendizado artístico profissional, que tinha como um de seus pressupostos a representação em pintura ou desenho do 
natural, por meio da observação direta dos objetos, paisagens ou pessoas. ${ }^{6}$ No caso dos alunos de Viaro, foram mencionados exercícios de figura humana realizados com "liberdade de estilo" (idem, ibidem). Em contrapartida, instituições como o Grupo Escolar Tiradentes foram representadas por trabalhos decorrentes do currículo oficial, tirados dos cadernos de classe dos alunos, tendo por objetivo "apresentar o desenvolvimento do desenho" (Exposição de Desenho..., 14 dez. 1943, p. 8), desde a primeira lição do primeiro ano até a última do quinto ano.

Outras discussões em voga naquele momento foram levantadas em alguns painéis da exposição, como a hereditariedade da aptidão artística, questionada em virtude dos resultados positivos apresentados por Constantino, filho do artista Guido Viaro, e a dúvida sobre se a influência dos gibis trazia malefícios para a expressão infantil, o que mereceu painel específico. Sugestões pragmáticas foram também contempladas, como conselhos fornecidos para a realização de pintura barata, feita com tinta de parede misturada à goma arábica, ou o exemplo dos desenhos dos alunos do Grupo Escolar Prieto Martinez, feitos com tintas extraídas do barro (Leite, 1943).

\section{PASSEIOS PELA EXPOSIÇÃO: O OLHAR DOS VISITANTES}

Durante o período em que esteve aberta, até o final de dezembro de 1943, a exposição foi visitada por cerca de duas mil pessoas, tendo sido baixada uma portaria, pela Diretoria Geral da Educação, recomendando a visita para os diretores dos grupos escolares e professores da capital e do interior do estado. $\mathrm{O}$ interventor Manoel Ribas, embora não tendo comparecido à inauguração, realizou visita especial ao certame, permanecendo "longo tempo no recinto, examinando todos os painéis e coleções de quadros, recebendo e pedindo informações sobre a interessante demonstração de arte infantil" (Exposição de Desenho..., 29 dez. 1943, p. 8). O evento também recebeu a visita de intelectuais, como o poeta Tasso da Silveira, Oscar Martins Gomes, presidente do Instituto dos Advogados, o desembargador Lacerda Pinto e Pereira de Macedo, professor da Universidade do Paraná (Exposição de Desenho..., 23 dez. 1943, p. 2).

O evento motivou espectadores e membros da organização a expressarem publicamente suas impressões e opiniões sobre as relações entre arte e educação. $\mathrm{O}$ valor psicopedagógico e o artístico da iniciativa foram enaltecidos em entrevista pelos artistas Theodoro de Bona, Guido Viaro e Oswaldo Lopes (Exposição de Desenho..., 16 dez. 1943, p. 3). De Bona ressaltava a importância do projeto para o desenvolvimento da cultura artística da criança. Já a necessidade de incentivo à liberdade de expressão foi assinalada por Viaro, que considerou a proposta de real importância, sobretudo para a faixa etária de até 12 anos. O artista ressaltou a necessidade de acompanhamento das crianças "em suas manifestações artísticas, dando-lhes ampla liberdade na escola a fim de que, pelo conhecimento dessas manifestações e sob o ponto de vista psicológico, seja possível verificar se evoluem ou retrocedem". Por fim, Lopes acentuou que o projeto deveria ser repetido em outras

6 Sobre os métodos de Andersen e de Viaro, ver De Bona (1982) e Osinski (2008). 
ocasiões, "a fim de que se permita uma continuidade na ordem de pesquisas, como as que foram realizadas e que tão fecundos resultados apresentaram" (idem, ibidem). Para a escritora Helvidia Leite (1943, p. 4), a mostra contribuiria para a revelação da riqueza da alma infantil, contemplando a liberdade dentro dos limites que uma proposta séria impunha: "foi um trabalho livre, mas houve orientação, houve espontaneidade mas também sistematização". Considerava a iniciativa paranaense mais bem-sucedida, se comparada com outra congênere, patrocinada pelo $O$ Globo Juvenil e levada a efeito na Associação Brasileira de Imprensa (ABI), no ano anterior, no Rio de Janeiro, a qual, embora muito concorrida e apreciada, "não deixava de ser uma exposição isolada", deixando as crianças "entregues aos seus próprios recursos, exclusivamente, procurando uma técnica de expressão". Isso fazia com que lançassem mão de seu "instinto de imitação" e que o desenho passasse a trazer a "marca do cinema, a influência da propaganda da guerra, etc.", fator que dava ao espectador a ideia de "uma insuficiência, de uma limitação". Ao pensar as influências do meio ou de pais e professores como prejudiciais, a autora seguia a linha de pensadores como Kerschensteiner, que em uma de suas experiências chegou a descartar trabalhos de vinte classes de alunos por esse motivo (Rouma, 1947, p. 22). Leite (idem, ibidem) via na exposição curitibana natureza diversa daquela organizada no Rio de Janeiro.

$\mathrm{Na}$ exposição de Curitiba há uma classificação, o desenho toma a função da linguagem e da música, e embora a criança obedeça a uma orientação ela traduz com mais segurança aquilo que vive dentro de si, exprime seus sentimentos, desejos e aspirações, adquire os meios que sua natureza requer para revelar as tendências do seu temperamento e faz promessa de progredir.

Comentando os trabalhos apresentados, concluía que, especialmente naqueles feitos de imaginação, era possível encontrar "um senso de arte, instintivo, espontâneo, infalível, esse senso que distingue o Homem, entre os seres da criação”(idem, ibidem).

A abordagem de temas específicos também foi objeto de artigos, como o de Ledi Cid (1943, p. 7), que procurou estabelecer relações entre a evolução da noção de espaço e as diversas fases de desenvolvimento infantil, seguindo os passos de investigadores interessados no desenho da criança, como William Stern, em suas pesquisas realizadas em Breslau, em 1905 (Rouma, 1947, p. 32). Cid compara os modos de representação espacial e as diferentes idades e fases de cada criança: enquanto os menores não apresentavam preocupação com essa questão, ocupando a folha do papel de forma mais desordenada, com o passar dos anos essa situação tendia a se modificar na direção de um maior cuidado com a definição dos elementos do espaço. $\mathrm{O}$ estabelecimento de uma linha representando o plano do chão ou a divisão da folha para a representação de diversas cenas sucessivas são exemplos desse tipo de preocupação citado pela autora. Esse processo culminaria, por volta dos 13 anos, ao chegar à fase do realismo visual, com a tentativa do uso da perspectiva para a representação do tridimensional.

Já no discurso de inauguração da mostra, publicado pelo jornal O Dia, Raul Gomes (Sociedade Amigos..., 14 dez. 1943) destacava duas lições tiradas pela iniciativa: a primeira versando sobre "o flagrante antagonismo entre a rigidez do 
programa oficial de desenho dos ginásios e os trabalhos de desenho livre", ali apresentados, e a segunda concernente "à ausência do ensino de desenho por mestres especializados na escola primária, lacuna digna de ser preenchida”.

Outros autores que evidenciaram o contraste da exposição organizada por Pilotto e Gomes em relação às mostras escolares foram os professores Francisco Thiago da Costa e Halina Marcinowska. Para Costa (Uma renovação..., 19 dez. 1943, p. 8), o referido certame representava "uma renovação nos conceitos das exposições escolares", mostras por ele criticadas por serem marcadas pela insinceridade e pela fraude - referência ao fato de que, no afã de mostrar bons resultados, muitas vezes os trabalhos eram realizados pelos professores ou pelos pais. Seriam elas de concepção fechada e monótonas, representando "como o fim de um processo, uma fase final, o repouso", constituindo "um corte vertical feito no último período de trabalho" e obedecendo "a um conceito estático" (idem, ibidem). A Exposição de Desenho Infantil e Juvenil, ao contrário, lembrava o movimento.

Nada tem de um corte. Nada tem de definitivo. Nada tem de estático. [...] Essa exposição vem de um trabalho que se vai processando e ela mesma não é fixa, mas é o levantamento de teses, de temas, o suscitamento de esforços novos, é um passo de uma marcha. (idem, ibidem)

O caráter progressista da proposta também foi ressaltado por Costa (idem, ibidem), ideia que estaria conectada a objetivos pedagógicos:

Está planejada para criar. Para que dela nasçam impulsos novos.

Tem um plano de prosseguir.

Quer apanhar essas crianças que expuseram aqui e acompanhá-las. Quer tomar os temas sugeridos aqui e iniciar a sua análise experimental. Quer recrutar as vocações e dar-lhes orientação sistematizada. Quer levantar os problemas nos espíritos. Quer sugerir criações, iniciativas. Quer de fato ter um futuro.

Por seu caráter dialético em relação às exposições escolares, a mostra seria quase um "congresso sobre o ensino de desenho", em que "levanta os temas, as teses, promove conferências, provoca estudos, discute, analisa, movimenta-se". Esse aspecto também se revelaria na dinâmica da organização, ao privilegiar o processo criador, a busca de novos caminhos e um "ambiente de autocrítica intensa e vital" (idem, ibidem).

A mesma percepção teve a atriz e professora de música e dança Halina Marcinowska (1943, p. 7), que, mesmo admitindo não ser uma especialista na área das artes plásticas, argumentou a favor da relevância do empreendimento. Em sua opinião, nos trabalhos apresentados revelava-se "o esforço, a espontaneidade, e um pedacinho da alma ingênua do pequeno desenhista" (idem, ibidem).

Contestando críticas feitas a alguns trabalhos expostos, que não passariam de rabiscos, a autora se posicionou em defesa da liberdade de expressão na infância:

Sim, mas como são belos estes rabiscos! Olhando-os, evoco a cabecinha inclinada sobre uma folha de papel, a mão ainda desobediente traçando riscos incertos, olhinhos brilhantes encobertos pelas pálpebras, os dentes mordendo a língua no 
esforço supremo da criação e a imaginação, larga imaginação sem limites, voa livre criando quadros tão belos que nenhum artista, dos maiores que a humanidade produziu, seria capaz de transportar para o papel ou para a tela. (idem, ibidem)

Marcinowska contrastava a proposta da mostra com sua própria experiência:

Quão diferente é este quadro daquele da minha infância! Papel, régua, borracha e na frente um horrível modelo, tão horrível na sua doçura inexpressiva do colorido e na falsidade das formas, como são inexpressivas as falsas rosas de papel. Traça-se um quadriculado sobre o modelo, outro no papel e, acompanhando o modelo, mede-se cinco milímetros prá cá, oito prá lá. Depois raspa-se a ponta dos lápis de cor, azul para o céu, azul mais carregado para as montanhas, verde para as árvores e com algodão espalha-se o pó esfregando uniformemente. Que trabalho desinteressante!

E se aqui no meio pintasse um camelo? Não, a professora se zangaria; isto é uma paisagem de montanhas. (idem, ibidem)

A autora se referia à metodologia da rede estimográfica, em vigor desde meados do século XIX, que propunha o ensino do desenho como reprodução de modelos bidimensionais por meio de uma malha quadriculada auxiliar (Barbosa, 2001, p. 35). Marcinowska lamentava que naqueles dias ainda não se compreendesse o grande valor do desenho e que no método de ensino ainda perdurassem "velharias que do dom espontâneo fazem um trabalho mecânico, desprovido de valor e de encanto da criação, deturpando talentos, matando o entusiasmo" (idem, ibidem).

Pelas exposições escolares realizadas paralelamente à Exposição de Desenho Infantil e Juvenil, tem-se uma ideia dos motivos das críticas de Costa e Marcinowska e do entusiasmo deles com a nova proposta. Embora o desenho, a modelagem, a dobradura e o recorte fossem por vezes contemplados, mesmo que por meio de metodologias consideradas arcaicas pelos educadores renovadores, a maioria dos estabelecimentos privilegiava trabalhos manuais que davam pouca liberdade de criação aos seus executores ou que mostravam um nível de perfeição que colocava dúvidas sobre sua autoria. A exposição realizada pelos alunos do Grupo Escolar Prieto Martinez, por exemplo, apresentava naquele ano "trabalhos de alinhavo em profusão" [...] "almofadas, tapetes, bandejas, quadrinhos de serrilha, caixinhas, panos de cozinha, toalhinhas, sacolas de pão, etc." (Exposição de trabalhos..., 25 nov.1943, p.3). O mesmo acontecia com o Grupo Escolar Xavier da Silva, que impressionava os visitantes com "belíssimos trabalhos de costura e bordados", além de "almofadas e tapetes muito bem confeccionados" (idem, ibidem), ou com o Grupo Escolar Conselheiro Zacarias, que expôs "magníficos trabalhos realizados em linho branco", tais como "colchas, toalhas e guardanapos artisticamente trabalhados", impressionando o público pelo "cuidado, capricho e muito bom gosto com que foram feitos" (Grupo Escolar..., 27 nov. 1943, p. 3). Uma exceção nesse sentido foi a exposição realizada pelo Grupo Escolar Tiradentes, participante da mostra organizada por Pilotto, a qual se baseou, segundo a imprensa, em "inteligentes e racionais planos psicopedagógicos [...] de acordo com as diversas etapas do desenvolvimento da criança" (Grupo Escolar..., 30 nov. 1943, p. 3). 
O aspecto de falsidade das exposições escolares foi objeto de atenção de intelectuais como Cecília Meireles, já desde a década de 1930. Em crônicas bem-humoradas, Meireles denunciava a colaboração indevida de professores e familiares nos trabalhos atribuídos aos alunos. Para ela, o observador que percorresse as escolas no fim do ano ficaria surpreendido com a quantidade de coisas inúteis "que aparecem e se dão como executadas na escola”.

Primeiro: almofadas. Almofadas de tudo: de cetim Royal e de veludo, de linho e de gaze, de tussor e de feltro. Até de percaline, recortada, eu já vi! E até de papel crepom...

Depois, essa praga dos abajures... Fazem-nos de tudo: montados em arame, com rendinhas, babadinhos, pinturas a bico de pena, a óleo, com areia, com figuras de decalcomania, com franjas de vidrilho, de contas, de feijão colorido, de tubos de injeção vazios [...].

E, além de almofadas e abajures, uma infinidade de paninhos de renda, de seda, de linho, etc., etc., recortados, bordados, pintados, perfurados, - para a mesa, para a penteadeira, para as cadeiras, para mil lugares absurdos que a gente não é capaz de adivinhar...

Chamam a isso - arte... (Meireles, 2001, p. 29-30)

Meireles deplorava esses resultados verificados nas escolas municipais, que configuravam "o desvio que se produz na educação artística de uma criatura, com esses arremedos de arte, com essas tolices enfeitadas, com essas aberrações da fantasia, com esse delírio mórbido da imaginação", constituindo uma "manifestação tristíssima de vaidade mesquinha, que não se envergonha de se servir do nome das crianças para exibir a sua própria incapacidade" (idem, p. 32-33). A autora colocava em evidência um problema que não passava despercebido pelas autoridades cariocas, pois em 1930 o diretor da Instrução Pública publicou uma circular com instruções para que não se tolerasse que os trabalhos expostos pelos alunos fossem confeccionados por outras pessoas, prática condenada, considerada prejudicial por habituar a criança a falsear a verdade (idem, p. 51).

Embora as teorias psicopedagógicas dessem o tom de muitos dos discursos sobre o certame, alguns visitantes da Exposição de Desenho Infantil e Juvenil davam mais importância aos seus aspectos estéticos. Evitavam uma apreciação restrita aos critérios pedagógicos, que visam "acompanhar o desenvolvimento mental do indivíduo" e são mais um teste do grau de vivacidade e inteligência calculado quase que matematicamente. Buscando uma relação mais direta com a expressão infantil, afirmavam ter lhes chamado a atenção "aqueles trabalhos tanto mais livres quanto mais espontâneos na sua expressão plástica, aqueles que saem direto para o papel e que refletem uma ansiedade intraduzível no instrumento, por falta, exatamente, de aprendizagem elementar" (Arte infantil, 24 dez. 1943, p. 3). Reflexos da expressão inata da criança, nesses trabalhos é que estariam "talvez os melhores retratos deste mundo misterioso e fascinante e que os artistas maduros desesperadamente buscam exprimir" (idem, ibidem). 


\section{CONSIDERAÇÕES FINAIS}

A Primeira Exposição de Desenho Infantil e Juvenil do Paraná se inseriu num contexto de valorização da espontaneidade e da individualidade da criança, manifesta por meio de ações como a Semana da Criança ou a criação do Departamento Nacional da Criança, e que se refletiu também na atenção dada à sua produção artística. Tendo como antecedente direto a Exposição de Crianças Inglesas, organizada por Herbert Real, além das mostras escolares, relaciona-se, por um lado, com a tradição das exposições no campo da arte e, por outro, com a prática de realização desse tipo de evento para evidenciação de ideias e defesa de pontos de vista.

A organização do projeto, ao cargo da Escola de Professores e da Sociedade Amigos de Alfredo Andersen, foi composta por intelectuais identificados com as ideias renovadoras para o ensino da arte, como Erasmo Pilotto e Raul Gomes, conquistando a chancela governamental e mobilizando grande número de participantes e de visitantes. Com o intuito de conferir ao certame caráter de investigação científica, esses intelectuais se apoiaram nas ideias de pesquisadores como Rabello, Luquet e Rouma, e nas conclusões de eventos como o Congresso de Paris de 1937, o que se percebe pela adoção de um léxico especializado e disseminado no meio especializado da psicologia do desenho infantil. Essa pretensão de cientificidade foi contrabalançada pelo envolvimento de artistas como Guido Viaro, Freyesleben e Oswaldo Lopes, cujos olhares podem ter direcionado as escolhas também com base em critérios estéticos.

O desejo de contemplar setores do meio social, como as escolas profissionais de arte de Viaro e Andersen e os programas oficiais de ensino de desenho, também pode ter comprometido relativamente a coerência da proposta, resultando na inclusão de resultados ligados a correntes metodológicas mais tradicionais.

O caráter supostamente democrático da iniciativa pode ser questionado em virtude da adoção de um processo de seleção que contemplou um número relativamente pequeno de participantes. Também a ideia de "caça às vocações", remetendo à concepção do talento inato, contrariava os próprios referenciais adotados, mais preocupados com o desenvolvimento infantil de um modo geral que com o incentivo à criação de futuros artistas. No entanto, o envolvimento de alunas formandas da Escola de Professores, bem como a elaboração de um guia para melhor compreensão da mostra, denota preocupação pedagógica não só no nível da formação profissional das educadoras, mas também do público espectador.

Nota-se, nas diversas manifestações divulgadas nos artigos de jornal, que muitos visitantes viam na iniciativa um caráter de ineditismo e renovação. Percebiam também um contraste entre a exposição organizada por Pilotto e as exposições escolares: o incentivo à liberdade de expressão e à espontaneidade infantil, presente na primeira, estaria em contraposição aos resultados expostos nas escolas, mais ligados aos trabalhos manuais e muitas vezes realizados com a ajuda dos adultos, pais e professores, ou que refletiam a rigidez característica dos programas oficiais de ensino de desenho. A constatação dessa situação gerou diversas críticas ao sistema escolar, remetendo à importância da adoção de uma perspectiva mais moderna com 
relação ao ensino e à necessidade da contratação de professores especializados em desenho nas escolas.

Fruto da confluência de referenciais oriundos tanto do campo da arte como da educação, a experiência resultante na Primeira Exposição de Desenho Infantil e Juvenil foi pioneira no contexto paranaense, descortinando horizontes para outras iniciativas que se seguiriam no intuito do respeito às peculiaridades da criança $\mathrm{e}$ da expressão artística infantil. Por meio dela, temos acesso a alguns aspectos do debate sobre as relações entre educação e arte em curso no período, sendo possível também enxergar, mesmo que por uma fresta, um pouco da criança e de sua arte e do olhar dos adultos sobre elas.

\section{REFERÊNCIAS}

A palavra do ministro da educação. O Dia, Curitiba, p. 4, 17 set. 1943.

A proteção À infância no estado. O Dia, Curitiba, p. 4,29 out. 1943.

A próxima Exposição Infantil e Juvenil da Sociedade Amigos de Alfredo Andersen. O Dia, Curitiba, p. 7, 14 nov. 1943.

Arte infantil. Gazeta do Povo, Curitiba, p. 3, 24 dez. 1943.

As iniciativas interessantes. O Dia, Curitiba, p. 4, 9 nov. 1943.

Azevedo, Fernando de et al. Manifesto dos Pioneiros da Educação Nova (1932) e dos educadores (1959). Disponível em: <http://www.dominiopublico.gov.br/download/ texto/me4707.pdf>. Acesso em: 20 out. 2013.

Barbosa, Ana Mae. John Dewey e o ensino de arte no Brasil. São Paulo: Cortez, 2001.

Brasil. Constituição (1937). Constituição dos Estados Unidos do Brasil. Rio de Janeiro: Presidência da República; Casa Civil; Subchefia para Assuntos Jurídicos,10 nov. 1937.

CAmpos, Raquel Discini de. No rastro de velhos jornais: considerações sobre a utilização da imprensa não pedagógica como fonte para a escrita da história da educação. Revista Brasileira de História da Educação, Campinas: Sociedade Brasileira de História da Educação (SBHE), v. 12, n. 1 (28), p. 45-70, jan./abr. 2012.

Cid, Ledi. A evolução da noção de espaço no desenho infantil. O Dia, Curitiba, p. 7, 19 dez. 1943.

Correia, Manoel Francisco. As crianças das ruas. O Dia, Curitiba, p. 4, 17 out. 1943.

Criança. O Dia, Curitiba, p. 4, 5 out. 1943.

De Bona, Theodoro. Curitiba: pequena Montparnasse. Curitiba: Imprimax, 1982.

Direitos da CRiança brasileira. O Dia, Curitiba, p. 3, 10 out. 1943.

Exposição de Arte Infantil e Juvenil. O Dia, Curitiba, p. 2, 21 nov. 1943.

Exposição de Desenho Infantil e Juvenil. Gazeta do Povo, Curitiba, p. 3,14 dez. 1943.

Exposição de Desenho Infantil e Juvenil. O Dia, Curitiba, p. 4, 11 dez. 1943.

. O Dia, Curitiba, p. 8, 12 dez. 1943.

O Dia, Curitiba, p. 8, 14 dez. 1943.

. O Dia, Curitiba, p. 3, 16 dez. 1943.

. O Dia, Curitiba, p. 2, 23 dez. 1943. 
O Dia, Curitiba, p. 7, 25 dez. 1943.

O Dia, Curitiba, p. 8, 29 dez. 1943.

Exposição do Pintor Th. de Bona. O Dia, Curitiba, p. 3, 7 set. 1943.

Exposição de trabalhos escolares. O Dia, Curitiba, p. 2, 19 nov. 1943.

O Dia, Curitiba p. 6, 23 nov. 1943.

O Dia, Curitiba, p. 3, 25 nov. 1943.

Exposição Guido Viário. O Dia, Curitiba, p. 3 , 5 out. 1943.

Exposição Infantil de Artes Plásticas. O Dia, Curitiba, p. 4, 11 nov. 1943.

Exposição Infantil e Juvenil de Artes Plásticas. O Dia, Curitiba, p. 8, 18 nov. 1943.

O Dia, Curitiba, p. 2, 23 nov. 1943.

O Dia, Curitiba, p. 4, 24 nov. 1943.

O Dia, Curitiba, p. 2, 26 nov. 1943.

Exposição Infantil e Juvenil de Desenho. O Dia, Curitiba, p. 8, 30 nov. 1943.

Feldman, Peter. Unity in identity, disunity in execution: expressions of french national identity at the 1937 Paris World's Fair. College Undergratuate Research Electronic Journal (CUREJ). Pensilvânia: 2006, [s.n.]. Disponível em: <http://repository.upenn.edu/ curej/52/>. Acesso em: 20 jul. 2012.

Forster, Simone. Du dessin aux arts plastiques. In: Landry, Françoise (Org.). À bonne école. Neuchâtel: Institut de Recherche et de Documentation Pedagogique, 2009.

Freyesleben, Waldemar Curt. Salão de fotografias. O Dia, Curitiba, p. 4, 26 nov. 1943. Gomes, Raul. Exposição De Bona, um acontecimento artístico. O Dia, Curitiba, p. 4, 7 set. 1943.

Gramsci, Antonio. Cadernos do cárcere. Tradução de Carlos Nelson Coutinho. Rio de Janeiro: Civilização Brasileira, 2004.v. 2.

Grupo Escolar Conselheiro Zacarias. O Dia, Curitiba, p. 3, 27 nov. 1943.

Grupo Escolar Tiradentes. O Dia, Curitiba, p. 3, 30 nov. 1943.

Instituto Nacional de Estudos e Pesquisas Educacionais (INEP). Escolinha de arte do Brasil. Brasília, 1980.

Leite, Helvidia. A natureza da criança vista através dos mais variados temperamentos. O Dia, Curitiba, p. 4, 21 dez. 1943.

Luquet, Georges-Henri. Sur les débuts du dessin enfantin. In: Congrès International D’Éducation Familiale. Biblioteca Nacional da França, BNF, 1910.

. Le dessin enfantin. Paris: Lebrairie Felix Alcan, 1927.

Magne, Marcel. Le 8e Congrès International de L'enseignemene du Dessin et des Arts Appliqués. In: Bulletin de la Société D’Encouragement Pour L'Industrie Nationale. Paris, 1938.

Marcinowska, Halina. Desenho infantil e juvenil. O Dia, Curitiba, p. 7, 23 dez. 1943.

Meireles, Cecília. Crônicas de educação. Rio de Janeiro: Nova Fronteira, Biblioteca Nacional, 2001. v. 4.

Miguel, Maria Elisabeth Blanck. A formação do professor e a organização social do trabalho. Curitiba: UFPR, 1997.

O ensino público nacional. O Dia, Curitiba, p. 4,22 dez. 1943. 
Osıns ki, Dulce Regina Baggio. A modernidade no sótão: educação e arte em Guido Viaro. Curitiba: Editora UFPR, 2008.

Paraná (Estado). Decreto n. 6.597, de 15 de março de 1938. Estabelece o regulamento das Escolas de Professores do Estado do Paraná. HISTEBR. Disponível em: <http:// www.histedbr.fae.unicamp.br/navegando/fontes_escritas/5_Gov_Vargas/paran\%E1\%20 decreto\%20n.\%BO\%206597 \%201938.htm>. Acesso em: 17 maio 2014.

Pesavento, Sandra Jatahy. Exposições universais: espetáculos da modernidade do século XIX. São Paulo: Hucitec, 1997.

Programa das comemorações da Semana da Criança. O Dia, Curitiba, p. 3, 9 out. 1943.

Rabello, Sylvio. Psicologia do desenho infantil. São Paulo: Companhia Editora Nacional, 1935.

Read, Herbert. Catálogo da Exposição de Desenhos Escolares da Grã-Bretanha. Londres: British Council, 1941.

Rouma, Georges. El lenguaje gráfico del niño. Buenos Aires: El Ateneo, 1947.

Será inaugurado hoje o Salão da Primavera. O Dia, p. 8, 12 out. 1943.

Sociedade Amigos de Alfredo Andersen. O Dia, Curitiba, p. 4, 14 dez. 1943.

SouzA, Rosa Fátima de. Templos de civilização: a implantação da escola primária graduada no estado de São Paulo: (1890-1910). São Paulo: Fundação Editora da UNESP, 1998.

Tarefas de alta relevância. Gazeta do Povo, Curitiba, p. 8, 18 dez. 1943.

Trabalhos de arte das crianças inglesas. O Dia, Curitiba, p. 2, 16 ago. 1942.

Trabalhos dos alunos do Instituto de Jovens Brasileiros. O Dia, Curitiba, p. 3, 3 out. 1943.

Um certame original e inédito. O Dia, Curitiba, p. 4, 28 nov. 1943.

Um espelho fiel da grandeza do Paraná. Gazeta do Povo, Curitiba, p. 5, 12 dez. 1943. Uma Renovação no conceito das exposições escolares. Palavras do professor Francisco T. da Costa sobre o certame de desenho infantil. O Dia, Curitiba, p. 8, 19 dez. 1943.

Vieira, Carlos Eduardo. Jornal diário como fonte e como tema para a pesquisa em história da educação: um estudo da relação entre imprensa, intelectuais e modernidade nos anos de 1920. In: Oliveira, Marcus Aurélio Taborda de. Cinco estudos em história e historiografia da educação. Belo Horizonte: Autêntica, 2007.

\section{SOBRE A AUTORA}

Dulce Regina Baggio Osinski é doutora em educação pela Universidade Federal do Paraná (UFPR). Professora da mesma instituição.

E-mail: dulceosinski@gmail.com

Recebido em setembro de 2012

Aprovado em janeiro de 2013 